\title{
Thingvellir, der isländische Nationalpark
}

Im Südwesten Islands, $50 \mathrm{~km}$ östlich der Hauptstadt Reykjavik, befindet sich der Thingvallavatn (Thingsee), der größte See auf der Insel. Er ist $83 \mathrm{~km}^{2}$ gro $B$, hat eine maximale Tiefe von $114 \mathrm{~m}$ und füllt ein tektonisches Becken aus. An seinem Nordufer breitet sich die Ebene von Thingvellir aus. Sie gehört geologisch und historisch zu den bedeutsamsten Gegenden Islands. Das Gesicht dieser Landschaft wurde von den Kräften einer eindrucksvollen, jungen Zerrungstektonik geprägt. Diese Kräfte ließen ganze Schollenpakete auseinanderweichen. Es bildete sich eine ungefähr $20 \mathrm{~km}$ breite, von parallelen Spalten durchzogene Zone, die von dem $1060 \mathrm{~m}$ hohen Schildvulkan Skjáldbreidur (Breiter Schild) ausgehend in Richtung Südwest bis hin zur Küste verläuft. Innerhalb dieser Spaltenzone sank dabei zwischen zwei Hauptspalten ein $5 \mathrm{~km}$ breiter Graben um mehr als $40 \mathrm{~m}$ in die Tiefe. Die Zerrungsspalten wurden zu Verwerfungen. Das durch diesen Grabenbruch entstandene Tal ist fast völlig von Stricklava bedeckt, die aus einer Spalte von der östlich der Talsenke gelegenen Hochheide Tindafjallaheidi kam. Auch in der Talsenke klaffen zahlreiche Spalten. Einige von ihnen, wie die berühmten Spalten Nikulásargjá und Flosagjá, reichen bis weit unter den Grundwasserspiegel. Sie sind mit langsam flieBendem Wasser gefüllt, das infolge der Filtrierung durch die Lava außerordentlich klar ist und eine gleichbleibende Temperatur von $3,3^{\circ} \mathrm{C}$ hat.

Die Absenkung fand vornehmlich in nacheiszeitlicher, aber prähistorischer Zeit statt. Noch 1789 sank bei einem Erdbeben der Landstrich zwischen der westlich gelegenen, von Nord nach Süd verlaufenden, $5 \mathrm{~km}$ langen Hauptspalte Almannagjá (Allmännerschlucht) und der die Senke im Osten begrenzenden, durch Staffelbrüche gekennzeichneten, Spalte Hrafnagjá (Rabenschlucht) um etwa $60 \mathrm{~cm}$. Der alte, ehrwürdige Thingplatz befand sich auf einem schwemmkegelartigen Abhang unmittelbar östlich der Almannagjá. Die westliche Felswand der Schlucht ist stellenweise $40 \mathrm{~m}$ hoch. Beim Absinken des Grabenbruchs hat sich an der östlichen Flanke der Schlucht eine langgestreckte Scholle tiefer gesenkt und dabei pultförmig schräggestellt. Ein Teil dieser Scholle wurde von den Begründern des Thingplatzes zum ,Lögberg' (Gesetzeshügel) bestimmt. Diese, heute durch einen Fahnenmast markierte Stelle wurde nur vom ,Lögmadur' (Gesetzesspre- cher) betreten, dem einzigen und zugleich höchsten Beamten des alten Island. Er verkündete von diesem kleinen Hügel aus die Gesetze, indem er sie laut gegen die aufragende westliche Felswand der Allmännerschlucht rief, diese als Echo benützend. Das Volk, das östlich von ihm auf dem niedriger gelegenen Thingplatz versammelt war, konnte so seine Stimme gut vernehmen.

In der Geschichte Islands spielt Thingvellir eine zentrale Rolle. Seit im Jahre 930 n. Chr. an dieser Stelle die Republik Island proklamiert worden war, versammelten sich hier alljährlich im Sommer für 14 Tage die Freien des Landes, um Althing (Parlament) zu halten. Für jeden freien Isländer war es Pflicht, am Althing teilzunehmen. Das bedeutete für viele, die im Norden und Osten beheimatet waren, einen mehrtägigen und beschwerlichen Ritt, der mit großen Gefahren verbunden war. Reißende Gletscherflüsse mußten durchquert, Lavafelder und tückische Moore umgangen werden. Besonders anstrengend war der Ritt durch die sich endlos dehnende Sandwüste des Sprengisandurs. Gefahr drohte auch von den Geächteten, die in der menschenfeindlichen Einöde der Lavawüsten ein kärgliches Dasein fristeten und gelegentlich den ahnungslosen Reitern auflauerten, um sie zu berauben. In vielen Sagen wird über Abenteuer dieser Art berichtet. Wer nicht am Althing teilnehmen konnte, der hatte einen Tribut zu entrichten, von dem die Kosten für das Althing bestritten wurden.

Doch das alljährliche Treffen in Thingvellir war für die Isländer, die ja keine Hauptstadt hatten, zugleich ein großes gesellschaftliches Ereignis. Berühmte Sänger, sogenannte "Skalden», die von ihren Besuchen an ausländischen Königshöfen zurückgekehrt waren, berichteten in ihren Gesängen von ihren Erlebnissen und waren gerne bereit, die wißbegierige Jugend in der Alliteration zu unterrichten. Die großen Epen der ruhmreichen Vergangenheit wurden hier vorgetragen und erstanden vor den atemlos Lauschenden aufs Neue.

In Thingvellir war es, wo Erich der Rote wegen Totschlag des Landes verwiesen wurde und nicht lange darauf, westwärts segelnd, Grönland entdeckte und mit seiner Sippe, die im Gebiet des Breidafjords in Westislands beheimatet war, besiedelte.

Im Jahre $1000 \mathrm{n}$. Chr. wurde in Thingvellir das Christentum auf friedliche Weise durch Mehrheitsbe- 
schluß eingeführt. Die Gegner der Einführung des Christentums benützten den Umstand eines Vulkanausbruchs südlich von Thingvellir auf der Halbinsel Reykjanes dazu, um zu behaupten, daß die Götter den Menschen zürnten, weil sie im Begriffe seien, sich von ihnen loszusagen. Die Befürworter der Einführung des Christentums dagegen sagten, warum denn die Götter nicht an Ort und Stelle, nämlich vor ihren Augen einen Vulkan ausbrechen ließen, um ihre Macht zu demonstrieren. Darauf wußten die anderen nichts mehr zu sagen, und so wurde das Christentum mit großer Mehrheit angenommen.

Erst 1789 wurde das Althing von Thingvellir nach Reykjavik verlegt, einem damals noch recht unbedeutenden, kleinen Fischerort. Unmittelbarer Anlaß für die Verlegung war das umseitig (oben) schon erwähnte Erdbeben, bei dem sich Thingvellir noch mal um $60 \mathrm{~cm}$ senkte.

Auch heute ist Thingvellir keineswegs vergessen. Am 17. Juni 1944, dem Geburtstag des großen isländischen Freiheitskämpfers Jón Sigurdsson, wurde hier die 2. Republik Island feierlich ausgerufen und die endgültige Loslösung von Dänemark verkündet. $\mathrm{Da}$ Thingvellir nur eine knappe Autostunde von Reykjavik entfernt ist, wird es häufig, besonders an den Wochenenden, besucht. Zahlreiche wohlhabende Reykjaviker haben sich am Westufer des Thingvallavatn ein Sommerhäuschen gebaut und benützen jede Freizeit dazu, um hinüberzufahren und die Stille und Erhabenheit der einzigartigen Landschaft zu genießen. Andere wieder schlagen ihre Zelte in Thingvellir auf, oder trinken Kaffee im Hotel Valhöll (Walhalla), das direkt unterhalb der Almannagjá, wenige hundert Meter von dem kleinen Kirchlein und dem kreisrunden Ehrenfriedhof entfernt ist, auf dem zwei bedeutende Dichter Islands aus dem 19. Jahrhundert, Einar Benediktsson und Jónas Hallgrimsson, beerdigt wurden. - Schon im letzten Jahrhundert schrieb der bekannte Weltreisende Lord Dufferin in seinem Buch «Letters from High Latitudes» (Briefe aus hohen Breitengraden), daß es die Mühe wert sei, eine Weltreise zu unternehmen, um Thingvellir zu sehen. Der gute Lord mag etwas übertrieben haben, doch steht fest, $\mathrm{da} ß$ man lange suchen muß, um einen Ort zu finden, der annähernd so interessant ist und zugleich so anziehend und lieblich, wie Thingvellir, das alte FORUM ROMANUM Islands.

\section{von Linden Franz-Karl und Weyer Helfried, Island, Kümmerly + Frey, Bern, 1974, Fr. 88.-}

Im Jahre 874, genau vor elf Jahrhunderten, begann die Besiedlung der fernen Insel im Nordatlantik. Seit dieser Zeit entstanden wohl Städte und Fischerdörfer längs der Küste, wurden die weiten Ebenen im Südwesten kultiviert und die tieferen Stufen der Fjordtäler mit einsamen Höfen und Weilern besetzt. Der größte Teil der Insel aber blieb ursprüngliche Naturlandschaft, geprägt durch den Antagonismus der Elemente Feuer und Eis. Sie spiegelt die Vielfalt vulkanischer Erscheinungen wieder, wobei in Island der alttertiäre Vulkanismus entlang einer aktiven Zone, die sich von Schottland bis Grönland erstreckte, ohne Unterbruch in den rezenten überging, der an den Mittelatlantischen Rücken geknüpft ist. Sie steht aber ebenso im Zeichen des sehr aktiven Einflusses einer imposanten Gletscherwelt. In Bild und Text vermittelt der vorliegende Band, erschienen in Erinnerung an die erste Hofgründung vor 1100 Jahren, einen umfassenden Überblick. Geologischen und naturgeographischen Faktoren wird ebenso Beachtung geschenkt wie Geschichte und Volkstum oder den wirtschaftlichen Gegenwartsproblemen. Ein Kapitel ist auch der mannigfaltigen Vogelwelt gewidmet. In Form der Saga ist die alte Geschichte Islands aufgezeichnet. Als moderne Saga fast mögen die Kapitel über die Entstehung der Vulkaninsel Surtsey und den jüngsten Vulkanausbruch auf Heimaey erscheinen, ergänzt durch Bilder, aus denen die volle Dramatik dieser Naturereignisse spricht. Nicht minder faszinierend kommt zur Darstellung, wie das Leben auf Surtsey das eben jüngst aus dem Meer aufgestiegene Land erobert.

Durch eine glückliche Zusammenarbeit von kompetenten Autoren und Photographen mit klarem Blick für das Wesentliche, sowie die treffliche $\mathrm{Zu}$ sammenstellung aussagekräftiger Bilder ist mit dem Band «Island» ein Werk gelungen, wie es in der umfangreichen Literatur über diese Insel bisher kaum zu finden ist.

Fritz Bachmann

Gegenüber: Originalfarbbild aus dem Bildband «lsland». 
